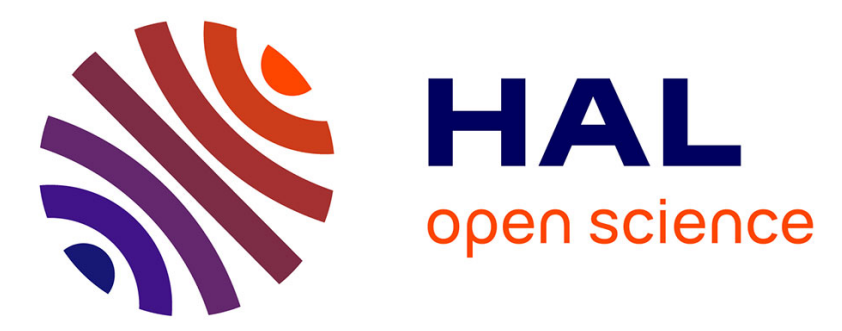

\title{
More than a decade of debates in the preeclampsia (island) workshops: a (personally biased) evolutionary perspective. \\ Gérard Chaouat
}

\section{- To cite this version:}

Gérard Chaouat. More than a decade of debates in the preeclampsia (island) workshops: a (personally biased) evolutionary perspective.. Journal of Reproductive Immunology, 2013, epub ahead of print. 10.1016/j.jri.2013.09.004 . inserm-00905597

\section{HAL Id: inserm-00905597 https://www.hal.inserm.fr/inserm-00905597}

Submitted on 18 Nov 2013

HAL is a multi-disciplinary open access archive for the deposit and dissemination of scientific research documents, whether they are published or not. The documents may come from teaching and research institutions in France or abroad, or from public or private research centers.
L'archive ouverte pluridisciplinaire HAL, est destinée au dépôt et à la diffusion de documents scientifiques de niveau recherche, publiés ou non, émanant des établissements d'enseignement et de recherche français ou étrangers, des laboratoires publics ou privés. 
More than a decade of debates in the Preeclampsia (island) workshops... A (personally biased $^{1}$ ) evolutionary perspective.

\author{
Dr Gérard Chaouat \\ U 976 INSERM. Pavillon Bazin. \\ Hopîtal Saint Louis \\ Avenue Claude Vellefaux. 75010. Paris. France. \\ +33153722064 gerard chaouat@wanadoo.fr
}

\begin{abstract}
In this short remembrance paper, I survey (what I believe are!) key events in the evolution of the concepts on preeclampsia from the $1^{\text {st }}$ workshop in 1998 to the 2012 one, and from Tahiti to Reunion island, via Mauritius and Tioman islands.
\end{abstract}

\title{
Keywords
}

preeclampsia, workshop, evolution, concepts, immunology

I will first start by an anecdote. It was April $1^{\text {st }} 1997$ and when coming back from lunch, my by then pre-doctoral student, Marlene Moussa, told me: Somebody has just phoned to invite you for a workshop in Tahiti.... I said it was a nice April fool's joke, but... A few days afterwards, Pierre Yves Robillard phoned me again, introducing himself, and saying he was planning to organize a workshop on preeclampsia in Tahiti... I realised it was not a joke, and accepted it. Memories of James Cook, La Pérouse, the Bounty, not to forget Alain Gerbaut, went to my mind, and suffice to say that the non scientific aspects of the meeting were above all expectations, including my dreams originated since the $1^{\mathrm{ST}}$ visions of Mel Gibson, Marlon Brando and Clark Gable renditions of Flechter Christian Polynesian Odyssey. We will always remember the trip from Papeete to Moorea in the ferry shuttle, the .... motor which stopped between the 2 islands, quickly fixed (ouf !) the entry in the bay of Opunahu and a welcome barbecue on the motu Tiahura......with our first swim in Moorea 's lagoon......

\footnotetext{
${ }^{1}$ I apologise to the many non quoted speakers. It does NOT mean THAT their work was not important, but space limitations and ...personal bias... obviously.... were at work.... The full report of each workshop was published in JRI.
} 
More seriously, this first meeting offered two opportunities: the first one was to meet the praticians and nurses at the antipodes, to whom we delivered a course. The $2^{\text {nd }}$ one was the workshop itself.

It was the first time we discussed together, and of course the main reason of the meeting was to discuss the new perspectives (at that time eventually) opened by the "challenge of the dogma" that Pierre Yves was launching about preeclampsia.

It should be recalled here that the prevailing theory was that preeclampsia was a vascular disease, and that any work speaking or even (mildly) invoking the existence (and even simply the possibility) of PE in a $2^{\text {nd }}$ pregnancy "should be immediately rejected without even consideration for publication"....( this "very scientific" approach, close to dictatorial censorship, IS unfortunately a quotation.....).

But Pierre Yves had been working in the French West Indies, mostly in Guadeloupe. He had observed that there was there indeed quite a lot of PE developing in multi gravidae. His study, co-authored with Emile Papiernik, dig the hole by the last sentences of the abstract: "for both primigravidae and multigravidae, length of sexual cohabitation before conception was inversely related to the incidence of pregnancy-induced hypertension $(p<0.0001)$. Similar results were observed after control for race, education, maternal age, marital status, and number of pregnancies. Pregnancy-induced hypertension may be a problem of primipaternity rather than primigravidity. Furthermore, an extended duration of sexual cohabitation before conception may protect against pregnancy-induced hypertension."

After several recalls of the concepts at the time, there were discussion on several key questions: a) can we definitively establish that there were significant numbers of $\mathrm{PE}$ in multigravidae b) does (do !) change (s!) of paternity affects the risk factor c) are there arguments for an immunological origin....

At the time, the main arguments for Immunology were, of course, the existence of specificity as well as memory. The replacement of the term primigravidity by primipaternity, if accepted, would tilt the balance towards specificity, whereas the fact that there were few PE in case of multiparity by the same father suggested a protective mechanism endowed with memory. The vascular theory, it was admitted, could explain the apparent protection (primigravidity) but had more difficulties in explaining the resurgence of the phenomenon in case of $2^{\text {nd }}$ occurrence linked to a change of biological father in multiparous women.

Another argument, of course, was the increased risk of PE in case of IVF, as well as the duration of sexual cohabitation, which enabled Gus Dekker to introduce the protective role of sperm exposure...

As far as Immunology was concerned, we had the chance of having the presence of Paul Terasaki, who explained us in term of suppressor $T$ cells (by then as they were named, since their discovery by Gershon and Kondo, and acronymed as Ts) in the (previously quasi heretical) "blood transfusion effect" being beneficial to kidney survival. But he also discussed the eventual involvement of enhancing antibodies and of anti idiotypes ones). Chris Redman was already there, and presented us his views on inflammation as the cause of preeclampsia. I 
had the feeling he was not necessarily convinced at onset by the immunological theories. The immunological theories themselves were in their infancy, for what was presented (and discussed) were mechanisms of foetal survival as an allograft, by myself, on one hand, and viewed from Polly Matzinger's danger theory (presentations by Elisabeth Bonney and Colin Anderson), and the "sea of cytokines" was briefly explored.

At the end of this $1^{\text {st }}$ workshop, the Immunologic theory had scored points, but it was the general opinion that a $2^{\text {nd }}$ workshop was obviously needed. That started the tradition for the workshop format (included in the format was that it should again be in an island. Not totally surprisingly, there were few to suggest such places as Bar Harbor, even though of historical fame, or similar Nordic locations).

In fact, Pierre Yves was forced to move from Tahiti to his now permanent residence, La Réunion, but organised the $2^{\text {nd }}$ workshop in Mauritius, in hotel "le Coco beach" in 2000. It was there that the search for "factor X", as Pierre would regularly name it, as a cause or consequence of Preeclampsia, started with the $1^{\text {st }}$ presentation by Thomas Rademacher of the role of Inositol phosphoglycans. Suffice to say it would be a continuous topic of all workshops till 2012, and that I will only re-quote briefly, until by then (2012) the recent study conducted by Lalita Poonith yielded further important evidence that it could be an easy, non invasive, test for detection and prognosis evaluation of PE, not to mention the role of IPG themselves in the disease.

Further clues were added : the role of sperm was further developed by Satish Gupta, the $1^{\text {st }}$ appearance of HLA-G was made by Debra Wohl, and the $1^{\text {st }}$ PE animal model was introduced by Sasaki Hayakawa....-it was a transfer of IL-12 hyper activated lymphocytes (a system which was grossly plagiarised later, as was indeed proved in Chicago after an official complaint).

But I would not say that, per se, this workshop represented a quantum leap in our knowledge.... The $3^{\text {rd }}$ workshop in 2002 was organised in another side of Mauritius, at "la Pirogue" ... and was really challenging and exciting. First, because the appearance of PE in evolution was tackled, with extremely provocative talk by Jean Chaline, linking increased cranial capacity in hominid evolution and preeclampsia. It was there that the price to pay for a big brain being PE was $1^{\text {st }}$ discussed, with the bold hypothesis that Neanderthal disappearance being related to the emergence of PE....Discussion wandered about this concept, with questions about existence of PE in great apes, (there was a talk from Robert Martin) and ... the Dolphin, as an example of large size brain and likely intelligence.

For the $1^{\text {st }}$ time, the NK cells made their intrusion, (be uNK cells be termed ...uNK or large granular lymphocytes) with the seminal (If I may permit) experiments of Anne Croy. The role of semen was proposed by Gus Dekker, and this was the $1^{\text {st }}$ appearance of the elegant studies of Sarah Anderson on the role of seminal plasma preparing maternal tolerance to the foetus. Also, this was the $1^{\text {st }}$ appearance in these meetings of HLA-G.

For the $1^{\text {st }}$ time, we came out with models: Ts/Tregs were proposed for the memory protective effect, by recognition of HLA-C, whereas NK were identified as "Janus cells" being either required and "good guys" for implantation and pregnancy, as angiogenic, or becoming bad 
guys as cytopathic/ cytototoxic cells. In this context, the Th1/ Th2 concept was revisited by Shigeru Saito.

IPG started to dig their hole.....

The demonstration by Lalita Poonith that occurrence of $2^{\text {nd }}$ pregnancy PE was strikingly different in two different Mauritian populations, (Indo Mauritians vs African Creoles).... where, very clearly, fidelity and paternity were culturally very differentially perceived, was another strong, though indirect, argument for immunologists.

We left this workshop with the clear sentiment that we had begun to set models for intervention of immunological factors in PE.

The next workshop in 2004 moved back to France, e.g. La Reunion (which is an integral French dept.), in the hotel lloha Saint Leu, where it would stay for long.

The $1^{\text {st }}$ part of the workshop clearly dig further the primipaternity concept, but for the $1^{\text {st }}$ time elements of a differential triggering of an NK cell : according to the receptor engaged, the activation could tilt the very same cell EITHER towards an angiogenic response or towards a cytotoxic one. Data proving the very existence of such dual patways were presented, as well as key (albeit debated) studies by Sue Hiby linking receptors families and HLA-C recognition. These studies introduced for the $1^{\text {st }}$ time the hitherto unsuspected positive role of a proper decidual NK KIR / Foetal HLA-C interaction while we presented positive and negative elements of the "Tripod". Chris Redman and lan Sargent presented their updated, and possibly for the $1^{\text {st }}$ time complete, view of the inflammatory continuum from normal pregnancy to PE, linked with the Th1 involvement by Shigeru Saito, and pathways of tolerance at the interface being explored by Shiko Sherjon, as well as Philippe Le Bouteiller for HLA-G.

The immunologic model and the links between immunology and angiogenesis, albeit fuzzy, began to emerge at the time, with links towards understanding the shallow invasion, characteristic to PE, as presented by Chandana Das. IPG (inositol phosphor glycans) continued to establish strong ground foundations for their role (Marco Sciocia and T Rademacher).

The $1^{\text {st }}$ real appearance of angiogenic factors in full perspective (this is not to say they were previously nowhere, see above what is said of Anne Croy and Sue Hiby) came at the $5^{\text {th }}$ workshop in 2006 with the talk of Anan Karumanchi introducing for the $1^{\text {st }}$ time the role of the VEGF / VEGF receptor family, with both a diagnosis / prognostic perspective, as well as s-flt1 as an element at the base of the syndrome. This was accompanied by the description of the role of NK cells in controlling utero foetal vascular development, and HLA-G as also an angiogenic factor...The competition for a diagnosis /prognosis tool between VEGF and IPG family started to become evident whereas, for the $1^{\text {st }}$ time, the regulatory pathways were discussed as such, with appearance under their "true" name of Tregs, and a key role of decidual lymphocytes. Further exploring inflammation and PE, the Oxford group began to present the role of micro particles. So that, for the $1^{\text {st }}$ time, the concept that immune deregulations could start very early was lingering.... 
Thus, the concepts were refocusing more and more on deregulations of innate immunity, themselves controlled by $T$ cells.

The strike of thunder in that respect came at the next workshop (2008), with clear demonstration that the VEGF/ s VEGF deregulation was liked to a very early complement dysfunction in a mouse model (the CBA $\times$ DBA/2 model, which I had never explored for PE, despite all the analogies I had pointed out between abortion in this mating combination and PE...). This exciting presentation by Guillermina Girardi confirmed that the somehow perceived feeling that PE was initiated very early was right, and opened the way for introduction of a new actor, the complement, whose positive and negative roles would also be precised in the next workshop by Francesco Tedesco. Complement attack, of course, or damage, could be linked easily to further developments of the Redman and Sargent model, while for the $1^{\text {st }}$ time the concept that an uNK cell contained both cytotoxic and angiogenic activities which could be chosen according to the type of triggered receptor was introduced by Philippe Le Bouteiller, and, of course, developments around the SVEGF/VEGF system were presented (Foidart, Wohl) while Tregs made an appearance "en force"...

Genes predisposition was tackled for the $1^{\text {st }}$ time by Daniel Vaiman and Thierry Fournier respectively...

The developments of the work on IPG were at the turning point......with a clear and complete description of the metabolic syndrome and insulin resistance (Scioscia, Rademacher).

At this point, the models had clearly made qualitative and quantitative changes. There were, I believe, no doubts that innate immunity was deeply involved (NK, Inflammation, complement), leading to deregulation of the VEGF pathway, whereas the T cell compartment was integral part of the "protective" and regulating arm, a part of it being possibly also under NK-HLA-C interactions control, as well as of dendritic cells, not to forget, of course, the multi faceted role of HLA-G.....

This was further demonstrated at the ante-penultian workshop in 2010, which moved from the Indian Ocean to Malaysian waters, in Tioman island, at the Berjaya complex, and this would lead to the present workshop, both of which I will not summarize, because for the Tioman (this is not an indication of failure of the workshop) there was no such quantum leap as introduction of innate immunity, VEGF, Tregs, complement (albeit the murine model for PE by Guillermina Girardi was investigated in full, and albeit NK Tregs did appear -Shigeru Saito- as well as MBL) safe for the fact that what I mentioned briefly, and which might have been perceived as a long road, the work on IPG, was crowned in 2012 by the study conducted in Mauritius by Lalita Poonyth, confirming the extraordinary predictive and diagnosis power of the IPG based test. See this volume. 


\section{References}

In this "remembrance paper", it would be (much !!!) too long a list to include all the references of all the papers stemming from the workshops, or related to the presentations which occurred. Even listing only those connected only to the major points described here would outflow the space limitations allotted to papers in the present issue.

As such, I will only include a (very) short chronological list of those papers, preface, JRI issues, and abstracts summarizing the workshops themselves in this journal, most of them, of course, stemming from the organising committee...

1) Chaouat, G., Robillard, P. Y., et al. 2005. Fourth International Workshop on Immunology of pre-eclampsia, December 2004, Reunion, France. J Reprod. Immunol. 67(1-2), 103111.

2) Proceedings of the 5th International Workshop on Reproductive Immunology, Immunological Tolerance and Immunology of Preeclampsia, La Reunion Island, November 2006. J. Reprod0 Immunol. 2007. 6(1-2), 1-97.

3) Proceedings of the Sixth International Workshop on Reproductive Immunology, Immunological Tolerance and Immunology of Preeclampsia. December 2008. Reunion Island. J Reprod Immunol. 2009. 82(2):95-181

4) Reproductive immunology, immunological tolerance and immunology of preeclampsia. Proceedings of the third international workshop. October 30-November 1, 2002. Mauritius Island. J. Reprod. Immunol. 2003 59(2), 85-294. Robillard, P.Y., Dekker, G., et a. 2009. Sixth International Workshop on Reproductive Immunology, Immunological Tolerance and Immunology of Preeclampsia. Preface. J. Reprod. Immunol. 82(2), 95.

5) Robillard, P.Y., Dekker, G., et al. 2011. Seventh International Workshop on Reproductive Immunology, Immunological Tolerance and Immunology of Preeclampsia, Tioman Island, Malaysia. Preface. J Reprod Immunol. 89(2),103. 


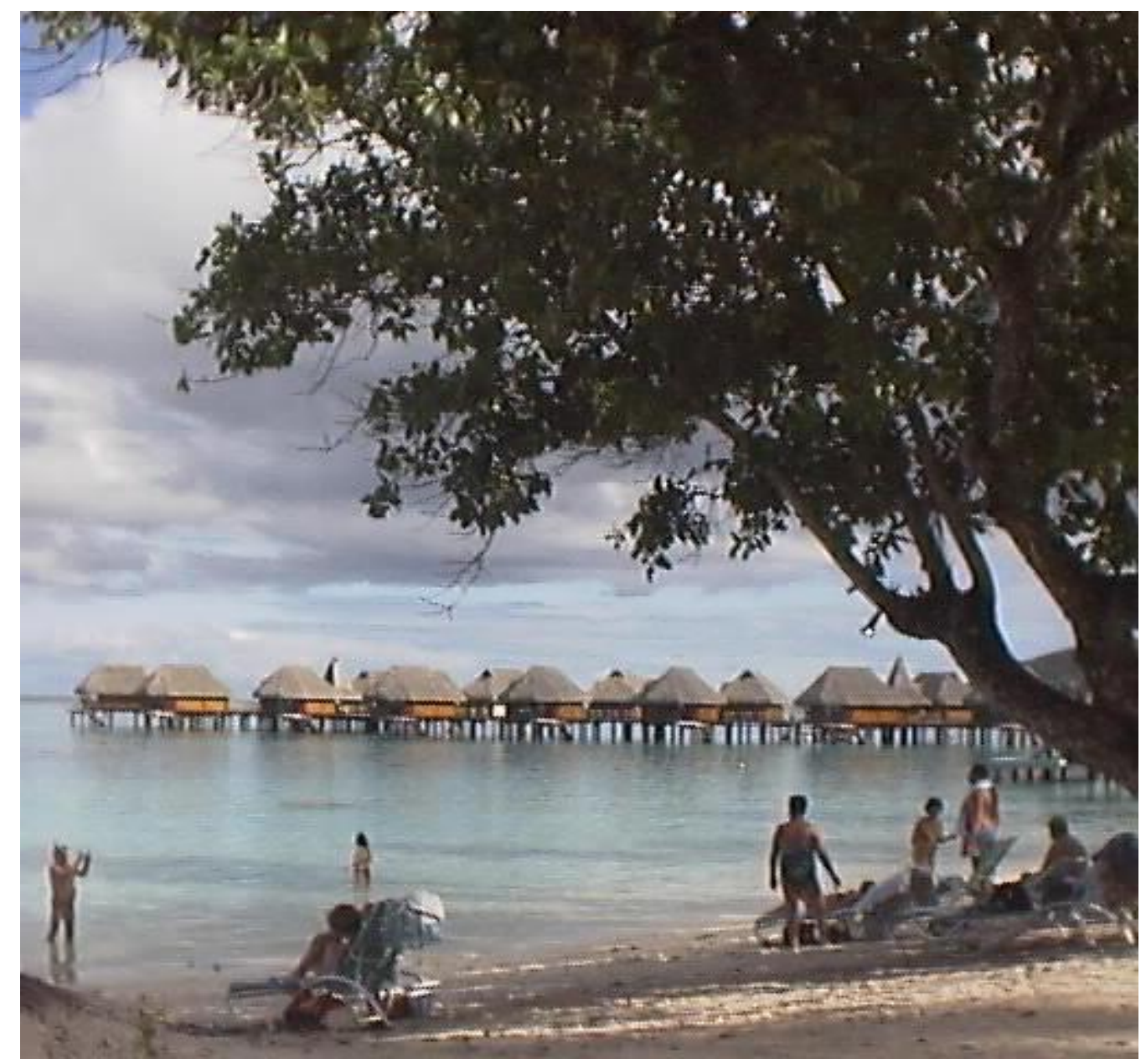

Mauritius : working sessions

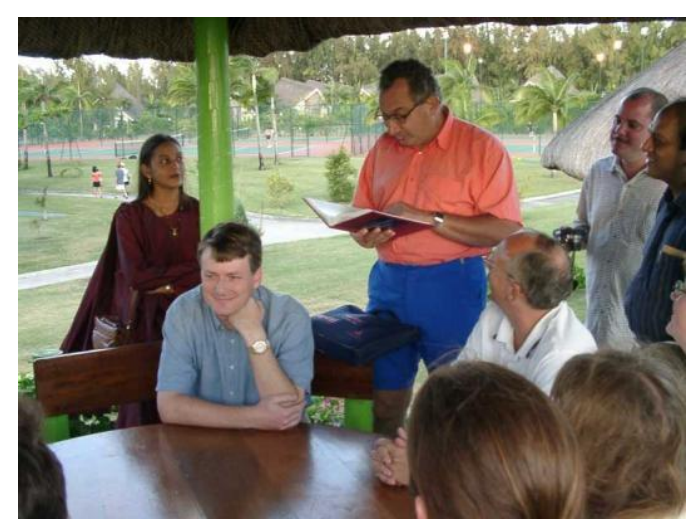

